\title{
Case Report \\ First Case of Esophagitis Dissecans Superficialis in an HIV Patient: A Case Report and Literature Review
}

\author{
Thaninee Prasoppokakorn $\mathbb{D i D}^{1}$ and Palakorn Panarat $\mathbb{D D}^{2}$ \\ ${ }^{1}$ Department of Medicine, Faculty of Medicine, Chulalongkorn University, Bangkok, Thailand \\ ${ }^{2}$ Department of Medicine, Queen Savang Vadhana Memorial Hospital, Chonburi, Thailand \\ Correspondence should be addressed to Palakorn Panarat; panarat_3rd@hotmail.com
}

Received 2 April 2019; Revised 27 May 2019; Accepted 13 June 2019; Published 2 July 2019

Academic Editor: Tomoyuki Shibata

Copyright (c) 2019 Thaninee Prasoppokakorn and Palakorn Panarat. This is an open access article distributed under the Creative Commons Attribution License, which permits unrestricted use, distribution, and reproduction in any medium, provided the original work is properly cited.

\begin{abstract}
Esophagitis dissecans superficialis (EDS), a rare desquamative esophageal disease of uncertain etiology, is characterized by sloughing of fragments of esophageal mucosa. To the best of our knowledge, there has been no reported case of EDS in an HIVinfected patient. We report the first case of EDS in an adult HIV-infected male, who was hospitalized due to dysphagia. Esophagogastroscopy was performed, and the endoscopic findings together with the histopathologic findings of esophageal tissues were consistent with EDS. However, his symptom of dysphagia was not explained by EDS, but was the early symptoms of musclespecific kinase (MuSK) myasthenia gravis (MG) that we finally diagnosed later by progression of the symptoms and electrophysiologic study. His symptoms had gradually improved after a course of intravenous immunoglobulin treatment. This is the first case of EDS and MuSK myasthenia gravis in an HIV-infected patient. A high index of suspicion of EDS should be made when taking care of the patients with desquamative or sloughing esophagitis especially with unknown etiology.
\end{abstract}

\section{Introduction}

Esophagitis dissecans superficialis (EDS), a very rare benign desquamative esophageal disease of uncertain etiology, is characterized by sloughing of large fragments of the esophageal squamous mucosa, followed by vomiting or regurgitation of the esophageal cast $[1,2]$. To date, there have been a few reported cases of EDS in the published literature; hence, accurate characterization of clinical features, etiology, pathologic findings, and outcomes are lacking [2]. We report herein the first human immunodeficiency virus- (HIV-) infected case with EDS and review all EDS case reports in the English literature.

\section{Case Report}

A 50-year-old male was hospitalized at Queen Savang Vadhana Memorial Hospital, Chonburi, Thailand, due to a 3-week course of oropharyngeal dysphagia. He had been diagnosed with HIV infection with a CD4 cell count of 64 cells/mL (8\%) 7 years prior, when he presented with a 2month history of chronic productive cough and significant weight loss. He received a combination treatment of tenofovir, emtricitabine, and efavirenz. Four months prior to the admission, he has achieved viral suppression with a CD4 count of 248 cells/mL (21\%). Physical examination revealed neither oral candidiasis nor other intraoral lesions. Esophagogastroscopy was performed and revealed diffuse pseudomembranes in the lower one-third of the esophagus (Figure 1). The histopathologic findings of the biopsied esophageal mucosa exhibited mild acute and chronic esophagitis with focal squamous hyperplasia without demonstrated organisms. A presumptive diagnosis of candidal esophagitis was made, and fluconazole of $200 \mathrm{mg} /$ day was prescribed to the patient. No clinical improvement was observed at 3 weeks after the start of antifungal treatment. Fluconazole dose was increased to $400 \mathrm{mg}$ /day. Three weeks after high-dose fluconazole treatment, he was rehospitalized 


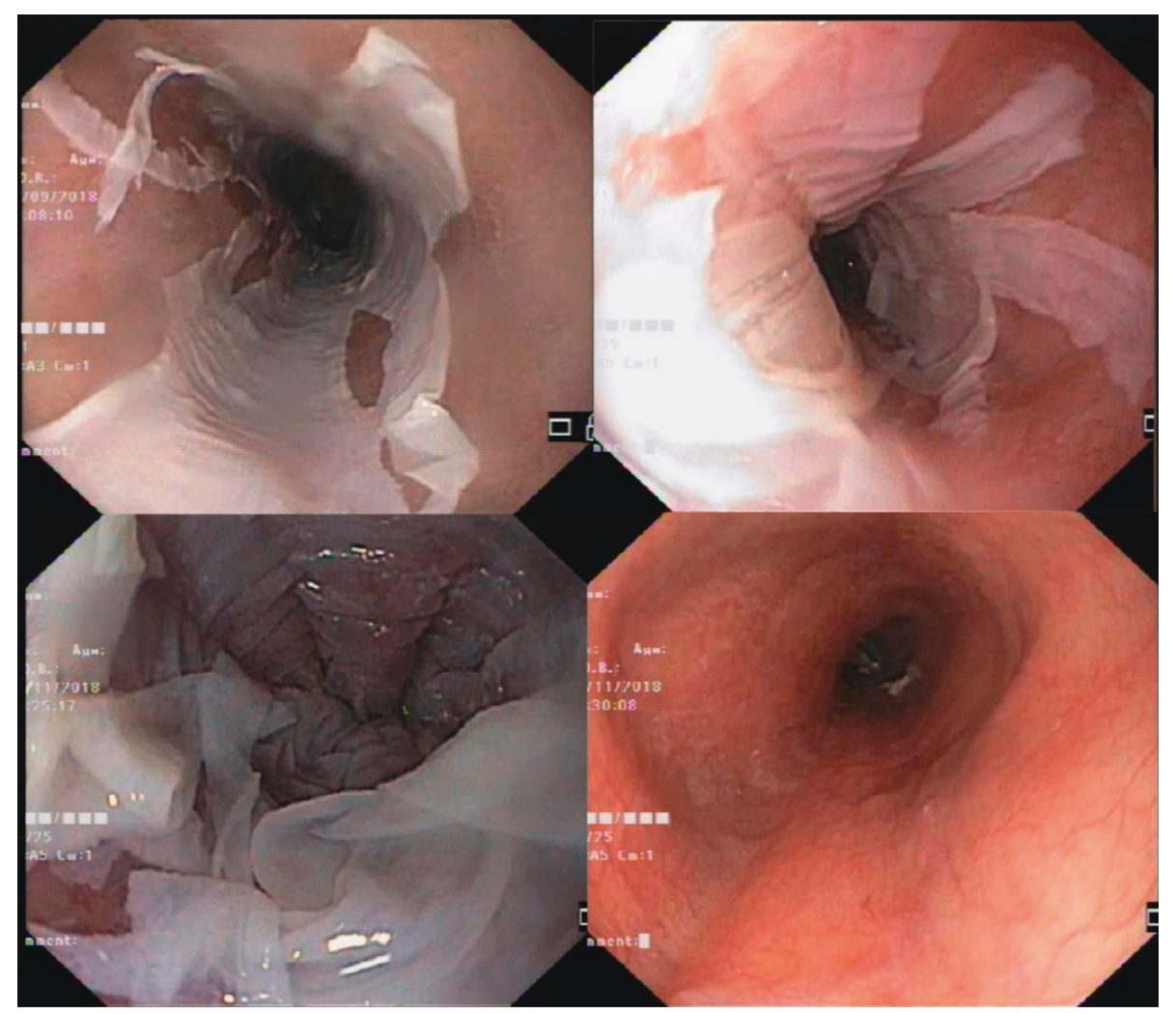

FIGURE 1: Esophagogastroscopy revealed diffuse pseudomembranes in the lower one-third esophagus.

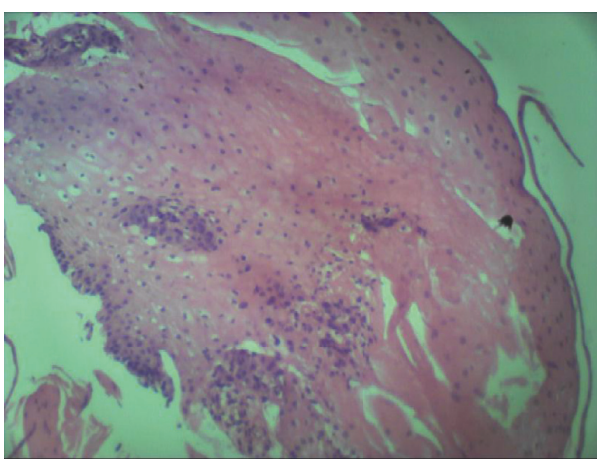

(a)

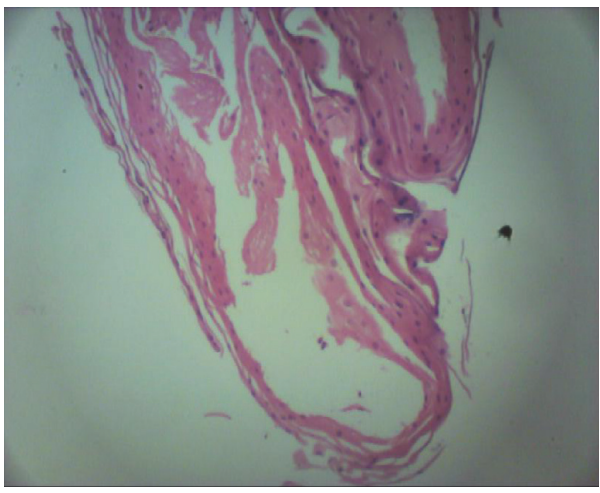

(c)

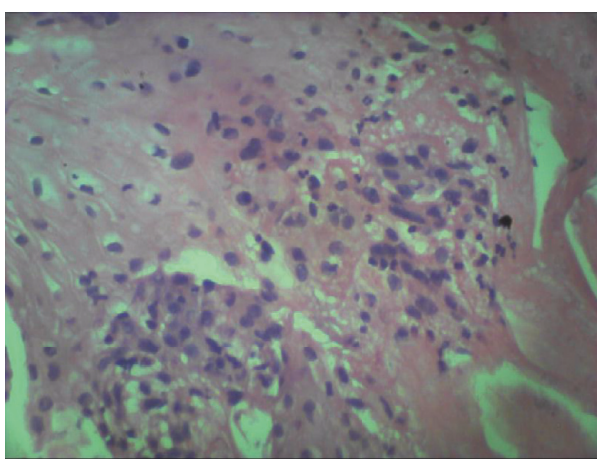

(b)

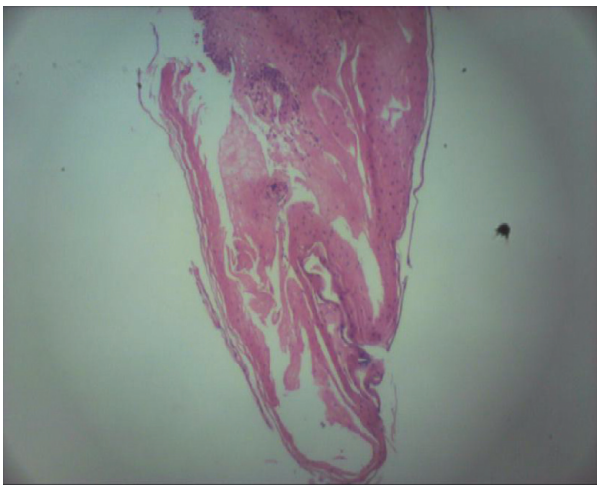

(d)

Figure 2: Pathologic findings of the lower esophagus revealed squamous cell hyperplasia (a), mild acute and chronic inflammatory infiltrations (b), a few small foci of splitting of the squamous epithelium (c), and a few intraepithelial cystic degenerations (d). 


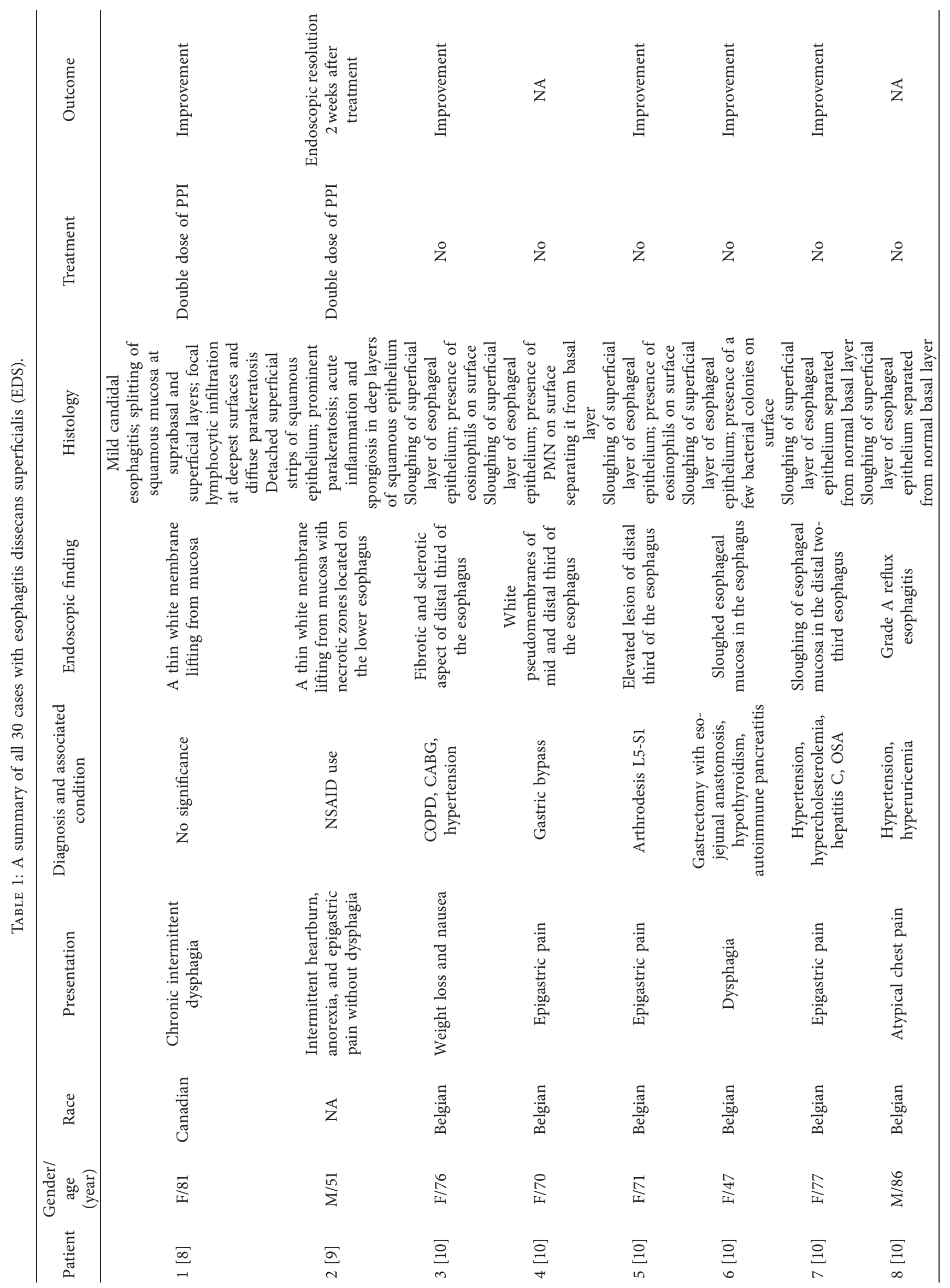




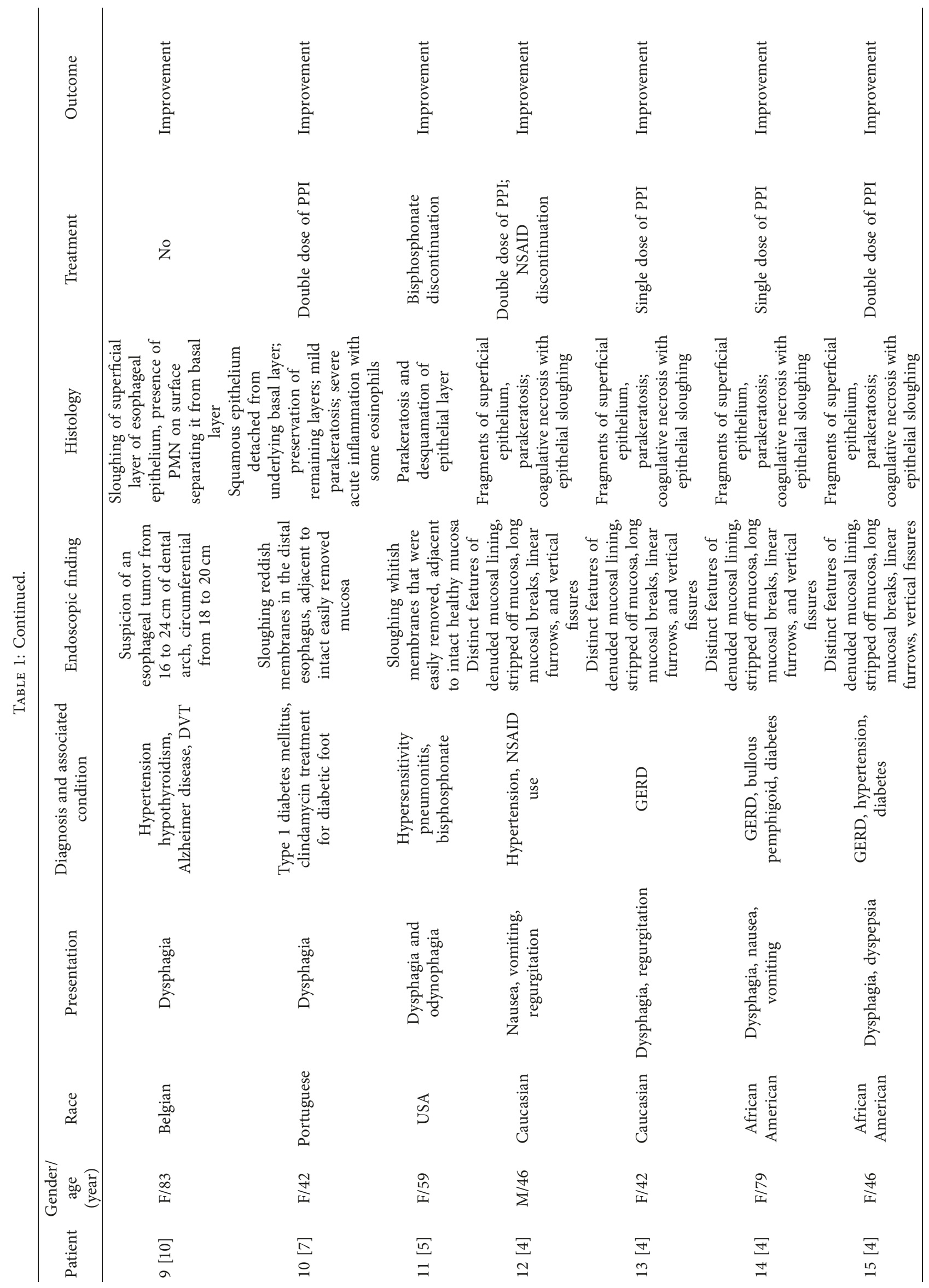




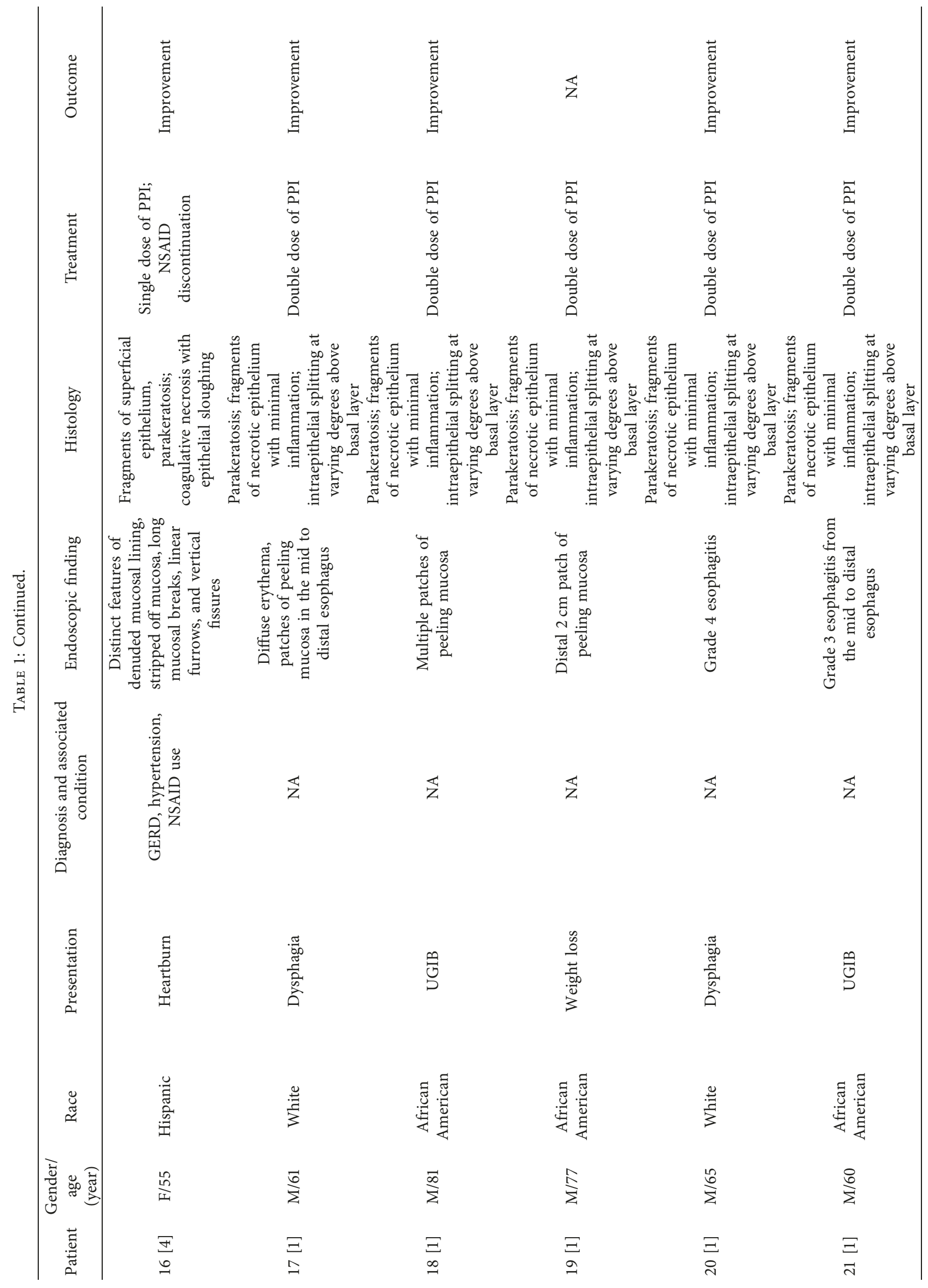




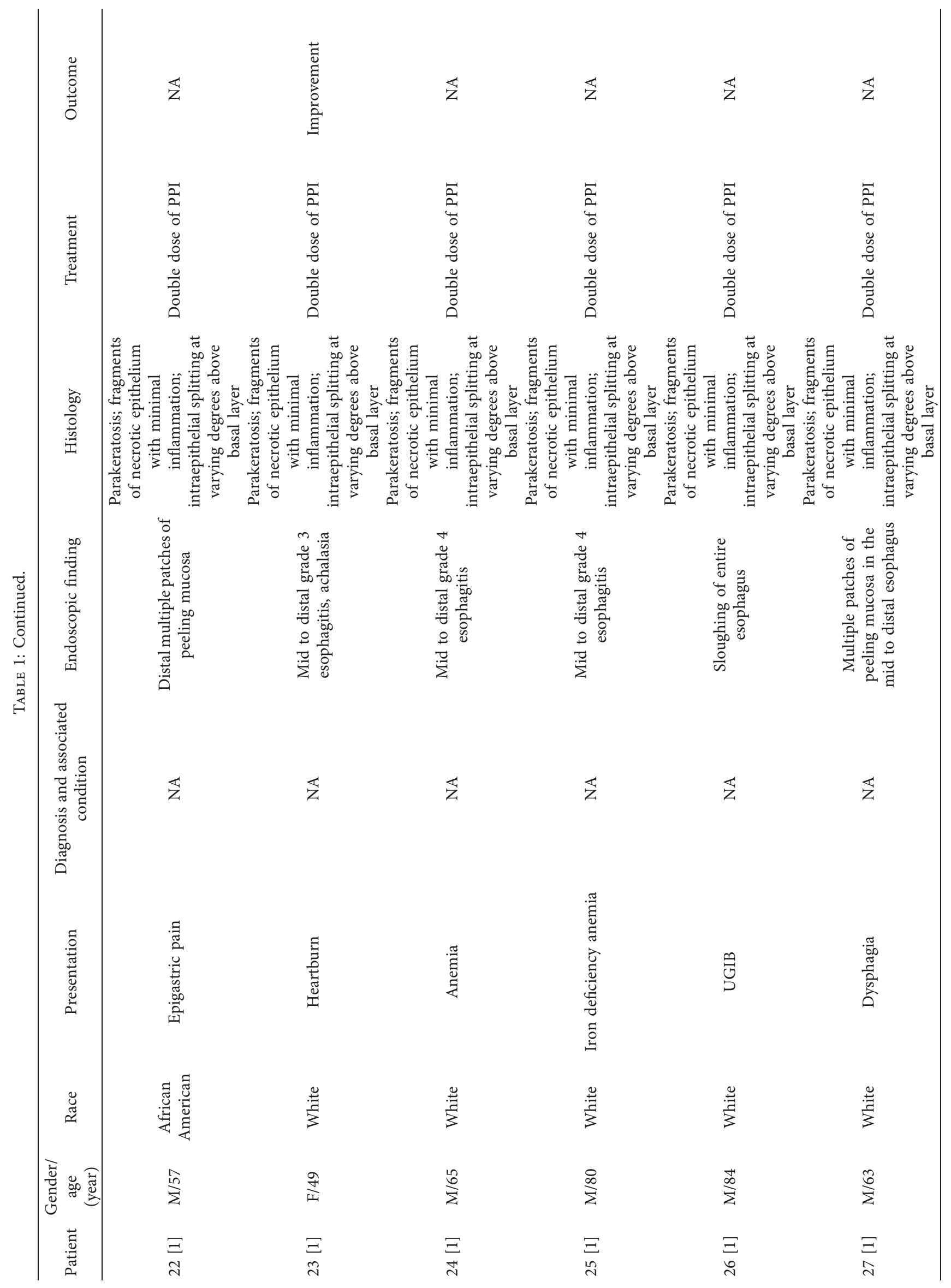




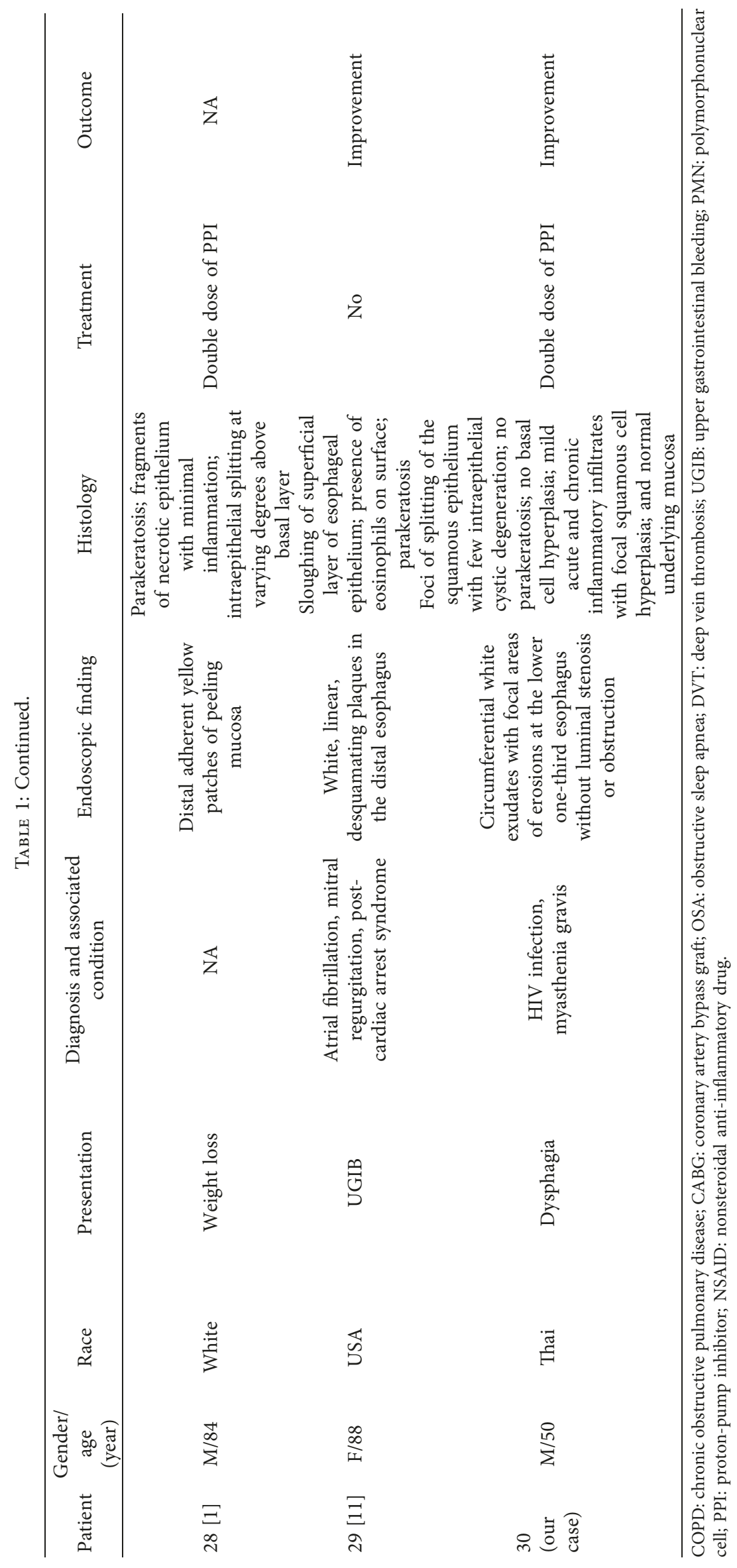


due to worsening condition and development of hypovolemic hyponatremia. Esophagogastroscopy was done once again, which revealed circumferential white exudates with focal areas of erosions at the lower one-third of the esophagus without luminal stenosis or obstruction. The pathologic findings exhibited foci of splitting of the squamous epithelium with few intraepithelial cystic degenerations, no parakeratosis, no basal cell hyperplasia, mild acute and chronic inflammatory infiltrates with focal squamous cell hyperplasia, and normal underlying mucosa, which were similar to the previous findings (Figure 2). A diagnosis of EDS was made, and omeprazole of $80 \mathrm{mg} /$ day was given to the patient. The patient's symptoms gradually improved after 2 weeks of treatment. During hospitalization, he developed binocular diplopia, proximal muscle weakness, and ventilatory failure requiring ventilator support. Myasthenia gravis was suspected. The diagnosis was confirmed by an electrophysiologic study and positive result of musclespecific tyrosine kinase (muscle-specific kinase, MuSK). The patient gradually improved after a course of intravenous immunoglobulin treatment.

\section{Discussion}

To the best of our knowledge, this is the first case of EDS in an HIV-infected patient. EDS is a rare self-limited desquamative esophagitis of unknown etiology, usually affects adults after the age of 50 [1]. It is likely underestimated and frequently misdiagnosed as in our case. The diagnostic criteria of EDS have not been established yet; however, the endoscopic and pathologic criteria were recently proposed by Hart et al. including the presence of all of the following features: (1) the strip(s) of sloughed esophageal mucosa of $>2 \mathrm{~cm}$ in length, (2) the normal underlying mucosa, and (3) the lack of ulcerations or friability of immediately adjacent mucosa [2].

The etiology of EDS is unknown. There have been many reports demonstrating the association of EDS with (1) drugs including nonsteroidal anti-inflammatory drugs $[1,3,4]$, bisphosphonates [5], potassium chloride [6], and clindamycin [7]; (2) celiac disease; and (3) autoimmune bullous dermatoses [6]. To date, there has been no report about the association of EDS and HIV infection, as in our case. Interestingly, due to lack of similar cases, the association between antiretroviral drugs and EDS required further studies. Similarly, the association between EDS and other immunodeficiency conditions has not been described. As a result, it is uncertain whether the HIV virus itself plays a role in the development of EDS. Furthermore, the association between EDS and MG also has never been reported. The presenting symptoms vary in different reports including dysphagia, heartburn, regurgitation, dyspepsia, upper gastrointestinal bleeding, anemia, and weight loss [2]. EDS is a benign condition that can resolve spontaneously or with the treatment with a proton-pump inhibitor (PPI) $[1,4]$. Our patient had protracted course of dysphagia for 6 weeks before clinical improvement with PPI treatment.

In addition, we review all 30 adult patients (including our case) with EDS [1, 4, 5, 7-11] (Table 1). There were 15 males and 15 females with the mean age of $65.8 \pm 14.9$ (range: 42-88) years. Our case is the first case with HIV infection. Regarding the race, there were 1 Asian (our case) and 28 Caucasians. The presenting symptoms included dysphagia (12 patients, 40.0\%), upper gastrointestinal bleeding $(4,13.3 \%)$, epigastric pain $(4,13.3 \%)$, heartburn (3, 10.0\%), weight loss $(3,10.0 \%)$, anemia $(2,6.7 \%)$, regurgitation $(1,3.3 \%)$, and atypical chest pain $(1,3.3 \%)$. Of 30 patients undergoing endoscopy, 21 (70.0\%) patients had the characteristic features of EDS (the distinct features of denuded mucosal lining or peeling mucosa of the distal esophagus). Of 30 patients, the histology of the esophageal biopsy exhibited the sloughing of superficial layer of epithelium (30 patients, 100.0\%), the presence of eosinophils on the surface $(4,13.3 \%)$, parakeratosis $(17,56.7 \%)$, and normal underlying mucosa $(2,6.7 \%)$. Of 30 patients with available data, all with (21 patients, $70.0 \%$ ) and without PPI treatment $(9,30.0 \%)$ had good outcome with both clinical and endoscopic improvement.

\section{Conclusion}

To the best of our knowledge, this is the first case of EDS in an HIV-infected patient. Due to lack of similar cases, the association between immunodeficiency conditions including antiretroviral drugs and EDS required further studies. EDS is a rare self-limited desquamative esophagitis of unknown etiology, which is diagnosed by excluding all other possible causes of oropharyngeal dysphagia. A high index of suspicion of EDS should be made when taking care of patients with desquamative or sloughing esophagitis especially with unknown etiology and/or no response to antifungal treatment.

\section{Conflicts of Interest}

The authors declare that they have no conflicts of interest.

\section{Acknowledgments}

The authors would like to express their sincere gratitude to Dr. Pongsak Chunpongthong and Dr. Tanate Jadwattanakul, who performed the first and second EGD, respectively. Furthermore, the authors would like to sincerely thank Dr.Paisal Parichatikanond, pathologist, who reported the results of histopathology from esophageal tissue for both occasions. In addition, the authors also specially thank the physicians at King Chulalongkorn Memorial Hospital and their team, who evaluated the patient and diagnosed MuSK MG along with appropriate treatment.

\section{References}

[1] S. Carmack, R. Vemulapalli, S. Spechler, and R. Genta, "Esophagitis dissecans superficialis ("sloughing esophagitis"): a clinicopathologic study of 12 cases," American Journal of Surgical Pathology, vol. 33, no. 12, pp. 1789-1794, 2009.

[2] P. A. Hart, R. C. Romano, R. K. Moreira, K. Ravi, and S. Sweetser, "Esophagitis dissecans superficialis: clinical, 
endoscopic, and histologic features," Digestive Diseases and Sciences, vol. 60, no. 7, pp. 2049-2057, 2015.

[3] J. K. Purdy, H. D. Appelman, and B. J. McKenna, "Sloughing esophagitis is associated with chronic debilitation and medications that injure the esophageal mucosa," Modern $\mathrm{Pa}$ thology, vol. 25, no. 5, pp. 767-775, 2012.

[4] D. Albert, M. Ally, and F. Moawad, "The sloughing esophagus: a report of five cases," American Journal of Gastroenterology, vol. 108, no. 11, pp. 1816-1817, 2013.

[5] R. S. Longman, H. Remotti, and P. H. Green, "Esophagitis dissecans superficialis," Gastrointestinal Endoscopy, vol. 74, no. 2, pp. 403-404, 2011.

[6] D. Jaspersen, "Drug-induced oesophageal disorders," Drug Safety, vol. 22, no. 3, pp. 237-249, 2000.

[7] J. R. Silva, R. Pinho, A. Ponte, M. Silva, A. Furtado, and J. Carvalho, "Esophagitis dissecans superficialis associated with severe clindamycin toxicity," Journal of Gastrointestinal and Liver Diseases, vol. 23, no. 4, p. 63, 2014.

[8] S. De and G. Williams, "Esophagitis dissecans superficialis: a case report and literature review," Canadian Journal of Gastroenterology, vol. 27, Article ID 923073, pp. 563-564, 2013.

[9] H. Lamine, B. Bochra, M. Mouna, E. Heykel, T. Monia, and A. Mohamed Masaddak, "Esophagitis dissecans superficialis due to severe nonsteroidal anti-inflammatory drugs toxicity," La Presse Médicale, vol. 47, no. 7-8, pp. 695-697, 2018.

[10] E. Fiani, F. Guisset, Q. Fontanges, J. Devière, and A. Lemmers, "Esophagitis dissecans superficialis: a case series of 7 patients and review of the literature," Acta Gastro-enterologica Belgica, vol. 80, no. 3, pp. 371-375, 2017.

[11] S. S. Brownschidle, E. K. Ganguly, and R. L. Wilcox, "Identification of esophagitis dissecans superficialis by endoscopy," Clinical Gastroenterology and Hepatology, vol. 12, pp. 79-80, 2014. 


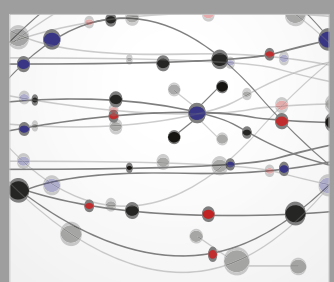

The Scientific World Journal
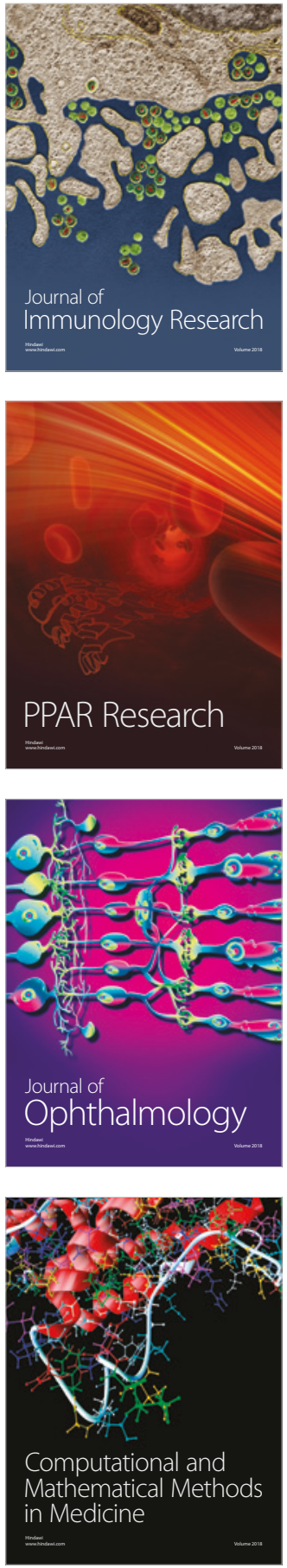

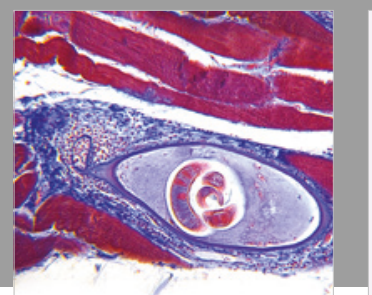

Gastroenterology Research and Practice

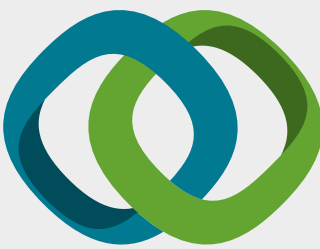

\section{Hindawi}

Submit your manuscripts at

www.hindawi.com
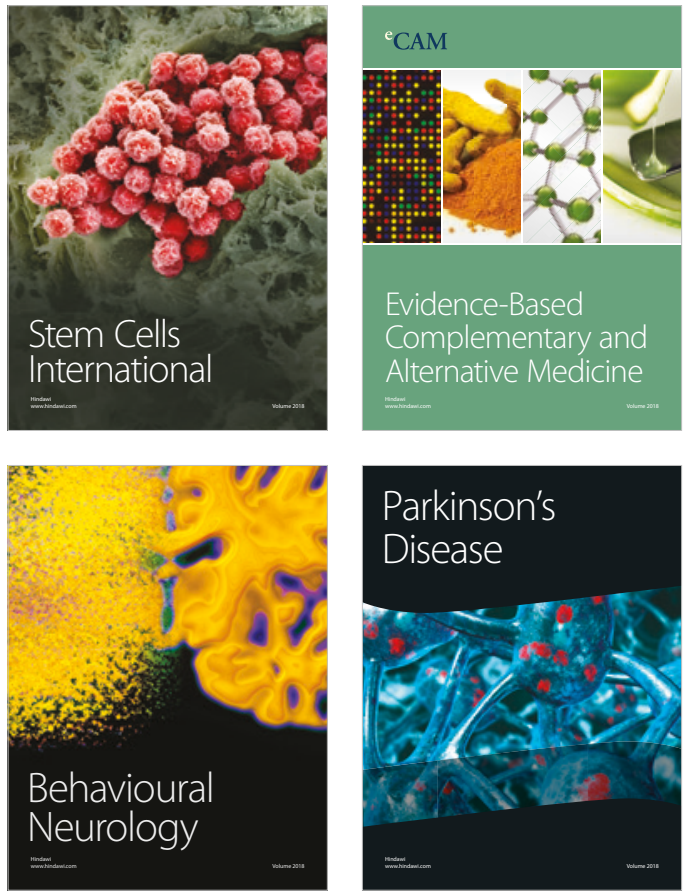

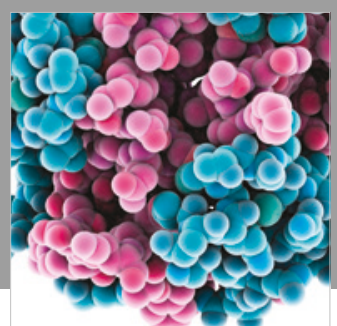

ournal of

Diabetes Research

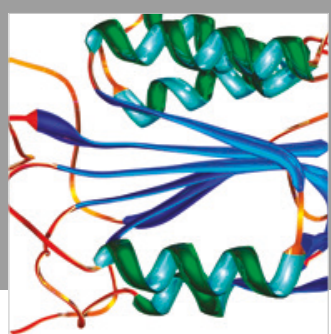

Disease Markers
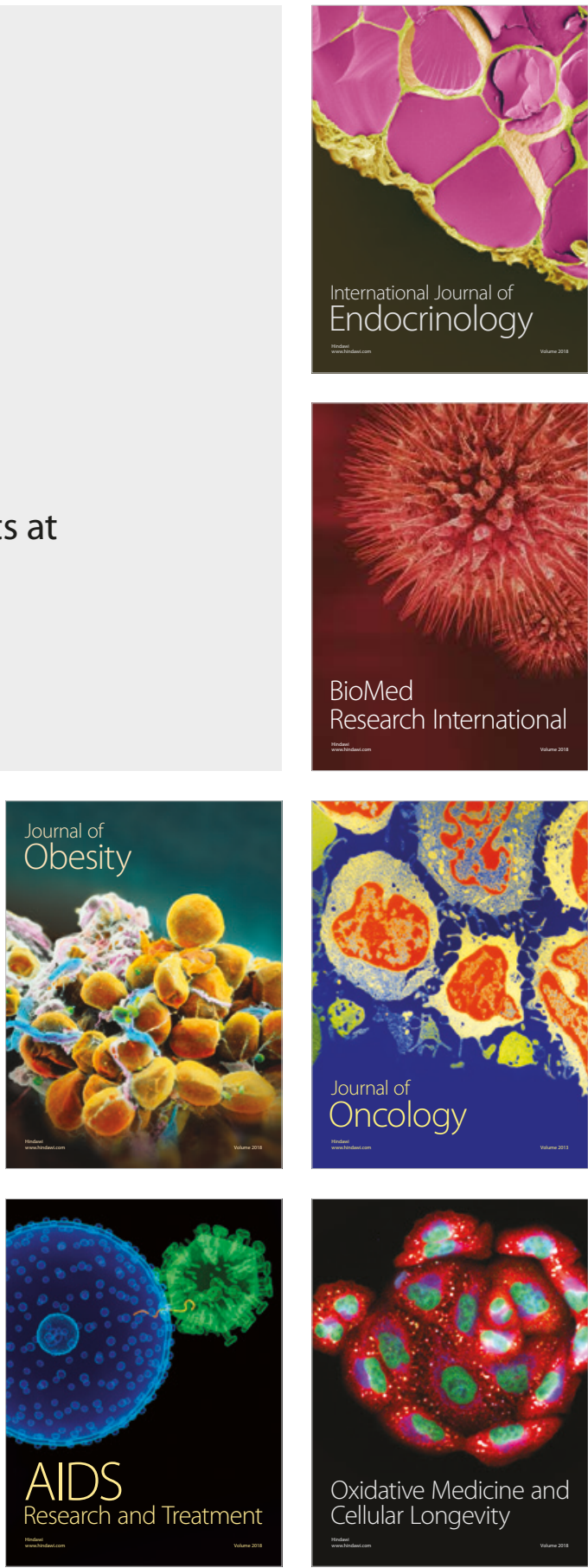